\title{
Organization of the mevalonate kinase $(M V K)$ gene and identification of novel mutations causing mevalonic aciduria and hyperimmunoglobulinaemia $D$ and periodic fever syndrome
}

\author{
Sander M Houten ${ }^{1}$, Janet Koster $^{1}$, Gerrit-Jan Romeijn ${ }^{1}$, Joost Frenkel ${ }^{2}$, Maja Di Rocco ${ }^{3}$, \\ Ubaldo Caruso $^{3}$, Pierre Landrieu ${ }^{4}$, Richard I Kelley ${ }^{5}$, Wietse Kuis ${ }^{2}$, Bwee Tien Poll-The ${ }^{1,2}$, \\ K Michael Gibson ${ }^{6}$, Ronald JA Wanders ${ }^{1}$ and Hans R Waterham*,1
}

\begin{abstract}
${ }^{1}$ Departments of Pediatrics and Clinical Chemistry, Emma Children's Hospital, Academic Medical Center, University of Amsterdam, Amsterdam, The Netherlands; ${ }^{2}$ Departments of General Pediatrics, Immunology and Metabolic Disorders, University Children's Hospital 'Het Wilhelmina Kinderziekenhuis', Utrecht, The Netherlands; ${ }^{3}$ Department of Pediatrics, Instituto 'G. Gaslini', Genova, Italy; ${ }^{4}$ Centre Hospitalier Universitaire Paris-Sud-Bicêtre, Laboratoire de Biochemie et Service de Neuropédiatrie, Le Kremlin-Bicêtre, France; ${ }^{5}$ Kennedy Krieger Institute and John Hopkins University School of Medicine, Baltimore, MD, USA; ${ }^{6}$ Oregon Health Sciences University, Department of Molecular and Medical Genetics and Biochemical Genetics Laboratory, Portland, OR, USA
\end{abstract}

Mevalonic aciduria (MA) and hyperimmunoglobulinaemia $D$ and periodic fever syndrome (HIDS) are two autosomal recessive inherited disorders both caused by a deficient activity of the enzyme mevalonate kinase (MK) resulting from mutations in the encoding $M V K$ gene. Thus far, disease-causing mutations only could be detected by analysis of $M V K$ cDNA. We now describe the genomic organization of the human MVK gene. It is $22 \mathrm{~kb}$ long and contains 11 exons of 46 to $837 \mathrm{bp}$ and 10 introns of $379 \mathrm{bp}$ to $4.2 \mathrm{~kb}$. Three intron-exon boundaries were confirmed from natural splice variants, indicating the occurrence of exon skipping. Sequence analysis of 27 HIDS and MA patients confirmed all previously reported genotypes based on CDNA analysis and identified six novel nucleotide substitutions resulting in missense or nonsense mutations, providing new insights in the genotype/phenotype relation between HIDS and MA. European Journal of Human Genetics (2001) 9, 253-259.

Keywords: gene structure; mevalonate kinase; inborn errors; mevalonic aciduria; hyperimmunoglobulinaemia D and periodic fever syndrome; mutations

\section{Introduction}

The mevalonate pathway provides cells with isoprenoids that are vital for diverse cellular processes. The main end-products include prenylated proteins, heme A, dolichol, ubiquinone10, isopentenyl tRNAs and sterols. ${ }^{1}$ Currently, six inherited

\footnotetext{
${ }^{*}$ Correspondence: Hans R Waterham, Departments of Clinical Chemistry and Pediatrics (F0-224), Academic Medical Center, University of Amsterdam, P.O. Box 22700, 1100 DE Amsterdam, The Netherlands Tel: +31 20566 2618; Fax: +31 20696 2596;

E-mail: h.r.waterham@amc.uva.nl

Received 28 July 2000; revised 21 September 2000; accepted 29 September 2000
}

disorders have been described caused by defects in this pathway. Four of these, Smith-Lemli-Opitz syndrome, ${ }^{2-4}$ desmosterolosis, ${ }^{5}$ X-linked dominant chondrodysplasia punctata $^{6,7}$ and CHILD syndrome ${ }^{8,9}$ only affect the sterol biosynthesis. The two other disorders, mevalonic aciduria (MA; MIM 251170) and hyperimmunoglobulinaemia D and periodic fever syndrome (HIDS; MIM 260920) are caused by a deficient activity of mevalonate kinase (MK; E.C. 2.7.1.36). ${ }^{10-12} \mathrm{MK}$ is the first enzyme to follow 3-hydroxy3-methyl-glutaryl-CoA reductase (HMG-CoA reductase) in the mevalonate pathway and converts mevalonate into 5phosphomevalonate. In MA, the MK enzyme activity is usually virtually absent when measured in cultured skin 
fibroblasts of patients. ${ }^{10}$ In HIDS, however, a residual MK activity varying from 1 to $7 \%$ can be measured both in fibroblasts and leukocytes from patients. ${ }^{12}$ As a result of the MK deficiency, excretion of mevalonic acid in urine occurs, although the level of excreted mevalonic acid varies significantly between both syndromes. MA is characterised by a massive excretion (1-56 $\mathrm{mol} / \mathrm{mol}$ creatinine), while in HIDS the mevalonic aciduria is moderate (0.004-0.028 mol/ mol creatinine) and particularly observed during febrile crises. ${ }^{10,12}$ In controls, excretion of mevalonic acid in urine is less than $0.001 \mathrm{~mol} / \mathrm{mol}$ creatinine.

MA is a severe and often fatal multi-systemic disease, characterised by psychomotor retardation, failure to thrive, hepatosplenomegaly, anemia and recurrent febrile episodes. ${ }^{10}$ HIDS is a relative benign condition, in which patients suffer, as in MA, from recurrent fever episodes associated with lymphadenopathy, arthralgia, gastrointestinal problems and skin rash. ${ }^{13}$ Both syndromes have a recessive mode of inheritance and are rather rare. So far, approximately $20 \mathrm{MA}$ and 150 HIDS patients have been reported.

Both MA and HIDS are caused by mutations in the MVK gene encoding MK. In 12 of the 13 HIDS patients reported so far, one particular missense mutation, 1129G $>$ A (V377I), has been found. ${ }^{11,12}$ Most patients were compound heterozygotes for this common mutation and a second missense mutation that has been identified in both MA and HIDS patients, ${ }^{11,12,14-17}$ strongly suggesting that the $1129 \mathrm{G}>\mathrm{A}$ mutation is responsible for the HIDS phenotype.

Since the identification of $M V K$ as the disease-causing gene in both MA and HIDS most mutations could be detected only at the cDNA level due to the fact that the genomic structure of the $M V K$ gene was unknown. Analysis of cDNA isolated from lymphocyte preparations, however, often appeared troublesome probably due to instability of the MVK mRNA. Here, we report the genomic organisation of the $M V K$ gene, which now enables mutation analysis at the genomic DNA level. In addition, we confirmed our previously reported mutations at the genomic DNA level and identified six novel mutations in the MVK open reading frame (ORF).

\section{Materials and methods}

Resolution of the genomic structure of human MVK In order to identify the intron-exon boundaries, primer sets were designed on the MVK cDNA sequence to amplify potential intron sequences from genomic DNA by PCR. Care was taken that primers did not span potential splice junctions (consensus sequence A/CAG G/AG/T). Each PCR reaction contained $0.4 \mu \mathrm{M}$ of each primer (synthesized by Pharmacia), $10 \mathrm{~mm}$ Tris/ $\mathrm{HCl} \mathrm{pH} 8.4,50 \mathrm{~mm} \mathrm{KCl}, 0.01 \% \mathrm{w} / \mathrm{v}$ BSA, $0.2 \mathrm{~mm}$ dNTP (Pharmacia) and $1.5 \mathrm{U}$ Taq DNA polymerase (Promega). Each primer set was tested with 1.0, 1.5 and $2.0 \mathrm{mM} \mathrm{MgCl}_{2}$. Two different PCR programmes were used to amplify specific $M V K$ genomic DNA sequences. The 'standard' DNA amplification programme started with 2 min of denaturation at $96^{\circ} \mathrm{C}$, followed by 5 cycles of $30 \mathrm{~s}$ at $96^{\circ} \mathrm{C}$, $30 \mathrm{~s}$ at $55^{\circ} \mathrm{C}$ and $4 \mathrm{~min}$ at $72^{\circ} \mathrm{C}$, and 25 cycles of $30 \mathrm{~s}$ at $94^{\circ} \mathrm{C}$, $30 \mathrm{~s}$ at $55^{\circ} \mathrm{C}$ and $4 \mathrm{~min}$ at $72^{\circ} \mathrm{C}$ with a final extension step of $15 \mathrm{~min}$ at $72^{\circ} \mathrm{C}$. The 'touchdown' PCR programme was used for increased specific primer annealing and started with 2 min of denaturation at $96^{\circ} \mathrm{C}$, followed by 18 cycles during which the annealing temperature was lowered with $1^{\circ} \mathrm{C}$ per cycle from $72^{\circ} \mathrm{C}$ to $55^{\circ} \mathrm{C}$. Every cycle was initiated with $30 \mathrm{~s}$ of denaturation at $94^{\circ} \mathrm{C}$ followed by $30 \mathrm{~s}$ of annealing and 4 min of extension at $72^{\circ} \mathrm{C}$. These 'touchdown' cycles were followed by 20 cycles with $30 \mathrm{~s}$ at $94^{\circ} \mathrm{C}, 30 \mathrm{~s}$ at $55^{\circ} \mathrm{C}$ and $4 \mathrm{~min}$ at $72^{\circ} \mathrm{C}$ with a final extension step of $15 \mathrm{~min}$ at $72^{\circ} \mathrm{C}$. For amplification of large sequences we also used the Advantage cDNA polymerase mix according to the instructions of the supplier (Clontech). PCR products were sequenced from both ends by means of fluorescent labelled terminators on an ABI 377A automated DNA sequencer according to the manufacturer's protocol (Perkin-Elmer) and subsequently analysed for intron-exon boundaries. Intron sizes were estimated after electrophoresis of the PCR products on standard TBE agarose gels stained with ethidium bromide.

\section{Cloning of $M V K$ cDNA}

The open reading frame of the $M V K \mathrm{cDNA}$ was amplified by PCR using either primer set $M V K_{10-29}\left(5^{\prime}-\mathrm{cg}\right.$ ata gga tcc GAA GTC CTA CTG GTG TCT GC-3') and $M V K_{1195-1177}\left(5^{\prime}\right.$-cga tag gta CCT CTC AGA GGC CAT CCA G-3') or primer set MVK $-21--3$ (5'-tgt aaa acg acg gcc agt GCG GCA GGA TTC CCA GGA G-3') and $M V K_{1238-1219}$ (5'-cag gaa aca gct atg acc ATC CAG AAA GGG GCA TCT GG-3'). The first primer set introduced a 5' BamHI and $3^{\prime} \mathrm{Kp} n \mathrm{I}$ (underlined) and the second primer set a $5^{\prime}-21 \mathrm{M} 13$ and $3^{\prime} \mathrm{M} 13 \mathrm{rev}$ sequence (lower-case letters). The PCR products were ligated into the pGEM-T vector (Promega) and sequenced to characterise splice variants.

\section{Patients and mutation analysis of $M V K$ cDNA}

All patients studied, were diagnosed clinically with HIDS or MA and had strongly decreased activities of MK as measured in fibroblasts and/or lymphocytes making use of ${ }^{14} \mathrm{C}$-labelled mevalonate. ${ }^{18}$ Mutation analysis of $M V K$ cDNA was performed as described before. ${ }^{17}$

\section{Mutation analysis of human MVK on genomic DNA} Genomic DNA was extracted from fibroblasts, lymphocytes or lymphoblasts using the Wizard Genomic DNA Purification Kit according to the instructions of the supplier (Promega). Five sets of MVK specific primers with $-21 \mathrm{M} 13$ or M13rev extensions were used for amplification of the entire $M V K$ ORF encoded by exon numbers 2 to 11 . The sequences of these primers, the sizes of the resulting PCR fragments and the amplified exons are displayed in Table 1. For PCR amplification a 'touchdown' approach was used, in which the annealing temperature was lowered in 15 cycles with $1^{\circ} \mathrm{C}$ per cycle from 
Table 1 Primer sets used for PCR amplification of coding exons of the MVK gene

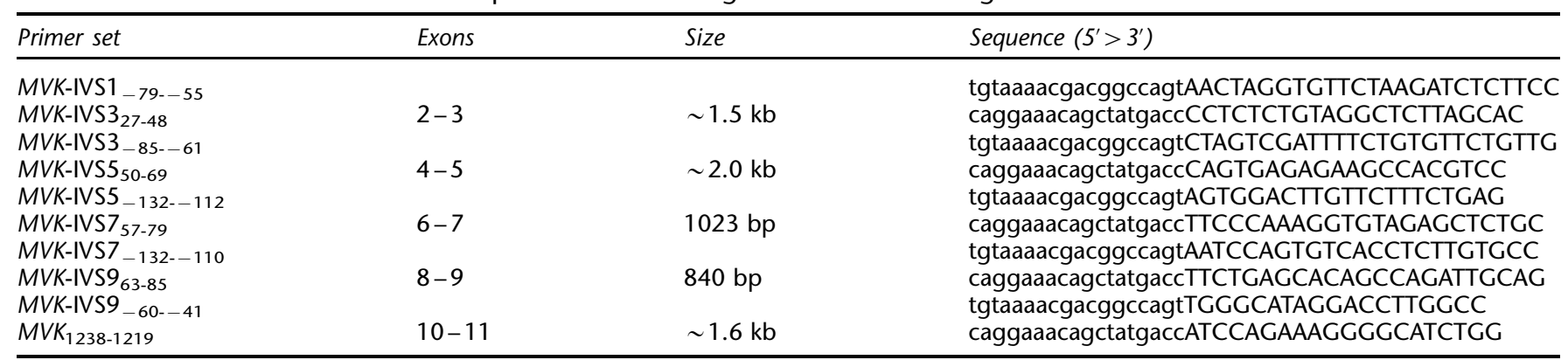

$72^{\circ} \mathrm{C}$ to $58^{\circ} \mathrm{C}$ as described above. The PCR fragments were sequenced by means of $-21 \mathrm{M} 13$ and M13rev fluorescent primers on an ABI 377A automated DNA sequencer according to the manufacturer's protocol (Perkin-Elmer).

\section{Northern blot analysis}

Total RNA was extracted from fibroblasts using the RNeasy mini kit according to the instructions of the supplier (Qiagen). After determining the RNA concentration, $15 \mu \mathrm{g}$ of total RNA was precipitated and used for electrophoresis on a formaldehyde agarose gel as described. ${ }^{19}$ The RNA was blotted onto a positively charged nylon membrane (Boehringer Mannheim) and visualised with $\alpha{ }^{32}$ P-labelled DNA probes. Hybridisation was performed overnight at $65^{\circ} \mathrm{C}$ in ExpressHyb hybridisation solution (Clontech).

\section{Results}

Resolution of the genomic structure of the MVK gene Previously, Schafer et al ${ }^{14}$ performed Southern blot analysis using a small radiolabelled $M V K$ cDNA probe and reported that $M V K$ was a single copy gene. Segregation analysis on chromosomal test panel blots and fluorescence in-situ hybridisation (FISH) mapped MVK on chromosome 12 position $\mathrm{q} 24 .^{14,20}$ Using four different cDNA probes together spanning the entire $M V K$ ORF we confirmed the existence of only one gene encoding MK (data not shown). In order to identify intron-exon boundaries in the $M V K$ gene, primer sets were designed on the $M V K$ cDNA sequence to amplify potential intron sequences from genomic DNA. Each primer set was tested under different PCR conditions. Amplified PCR products were sequenced and analysed for intron-exon boundaries. We found 11 exons ranging from 46 to $837 \mathrm{bp}$, with all intron-exon boundaries following the GT-AG rule (Table 2). Exon 1 encodes most of the 5 -untranslated region (UTR), exon 2 contains the ATG start codon and exon 11 contains the stop codon and the entire 3 '-UTR. The introns vary in size from $379 \mathrm{bp}$ to approximately $4.2 \mathrm{~kb}$. The sizes of two introns were determined from the actual nucleotide sequence (intron 6 and 8). All other intron sizes were estimated after gel-electrophoresis. Sequences are available at GenBank (accession numbers AF217527-35).

\section{Splice variants in MVK cDNA}

Amplification by PCR of MVK cDNA using different primer sets typically yielded not only a fragment of the expected size, but also two smaller specific PCR products (Figure 1). In order to test whether these are MVK splice variants, the PCR products were subcloned and sequenced. Both products contained deletions in the $M V K$ open reading frame, which introduce frameshifts resulting in truncated proteins. In the first product nucleotides 227 to 371 were deleted, which corresponds to the skipping of exon 4 . In the second product nucleotides 227 to 527 were deleted, corresponding to skipping of both exon 4 and exon 5 . In the course of our studies two additional rare splice variants were cloned. One of these variants contained an insert of $118 \mathrm{bp}$ at the position of intron 3 in the $M V K$ cDNA (GenBank accession no. AF217536). This splice variant is identical to a sequence in the expressed sequence tag (EST) database and contains an Alu repeat (GenBank accession no. AA403187). The mouse EST database also contains two clones with an in frame insertion of $36 \mathrm{bp}$ at the same position in the MVK cDNA (GenBank accession nos. AI121069 and AI121148). The second splice variant contained both this 118 bp insert and a $91 \mathrm{bp}$ deletion in the $M V K$ open reading frame from position 678 to 768 . This deletion corresponds to exon 8 .

\section{Mutation analysis of $M V K$ at the genomic DNA level}

Most previously reported mutations were identified after analysis of $M V K$ cDNA. The resolution of the $M V K$ gene structure enabled us to perform mutation analysis at the genomic DNA level. To this end the coding exons 2-10 and the coding part of exon 11 are amplified in five fragments using the primer sets displayed in Table 1. Chromosomal DNA was extracted from fibroblasts, lymphocytes or lymphoblasts of 27 patients of whom 17 displayed the HIDS phenotype and 10 the MA phenotype (Table 3). Table 3 includes only data of one affected member per family, in those cases that more members were identified. All 27 patients had strongly decreased activities of MK as measured in fibroblasts and/or 
Table 2 Positions and sizes of the exons and introns of the MVK gene and sequences of the intron-exon boundaries

\begin{tabular}{|c|c|c|c|c|c|}
\hline Exon no. & Size $(b p)$ & cDNA position & Splice acceptor & Splice donor & Intron size \\
\hline 1 & 77 & $-91--15$ & & GCGGCGGCAG/gtgagaggcc & $\sim 1.3 \mathrm{~kb}$ \\
\hline 2 & 92 & $-14-78$ & tcccttttag/GATTCCCAGG & ACATGGCAAG/gtacaaagcc & $\sim 1.1 \mathrm{~kb}$ \\
\hline 3 & 148 & $79-226$ & tattctatag/GTAGCACTGG & AGCTTTCTGG/gtgagtgcaa & $\sim 3.5 \mathrm{~kb}$ \\
\hline 4 & 145 & $227-371$ & tgtggaacag/AGCAAGGTGA & GGAAGCAGAG/gtgtgtgcgt & $\sim 1.5 \mathrm{~kb}$ \\
\hline 5 & 156 & $372-527$ & tgtgtttcag/GGCCCTGCCG & GCGTCAACAG/gtaaccatgg & $\sim 2.1 \mathrm{~kb}$ \\
\hline 6 & 104 & $528-631$ & gtgtcttcag/GTGGACCAAG & AGCACCTGGG/gtaggtgtgg & 626 bp \\
\hline 7 & 46 & $632-677$ & ttctctttag/GAGGAGCCCТ & CСТTAAAGAG/gtaacctggg & $\sim 4.2 \mathrm{~kb}$ \\
\hline 8 & 91 & $678-768$ & caccctgcag/GTCGCCAGCT & GCTGCTCAAG/gtgactcttg & 379 bp \\
\hline 9 & 117 & $769-885$ & ttttctccag/TTCCCAGAGA & CGTGCTGGAA/gtaagagcct & $\sim 3.8 \mathrm{~kb}$ \\
\hline 10 & 154 & 886-1039 & tctcccctag/GAGCTCATTG & CTCAAGCCAG/gtatcccggg & $\sim 1.2 \mathrm{~kb}$ \\
\hline 11 & 837 & 1040-1876 & ctccccgcag/GGCTGGAGCA & & \\
\hline
\end{tabular}

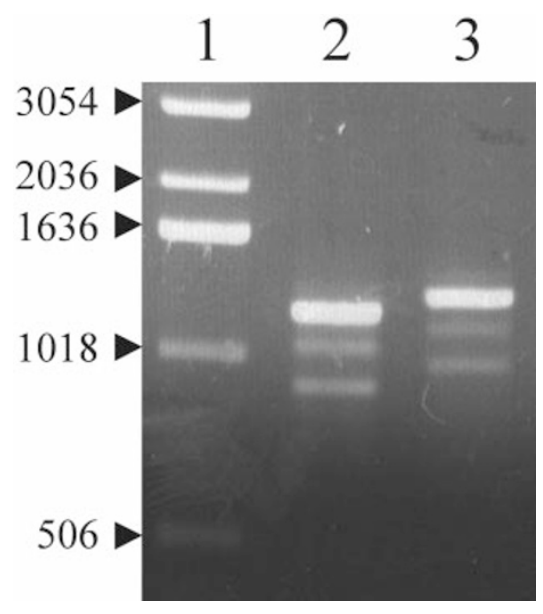

Figure 1 Amplification by PCR of MVK CDNA using two different primer sets revealed various splicing variants. Lane 1, DNA molecular weight standard; lane 2, MVK cDNA after amplification with primer set $M V K_{10-29}$ and $M V K_{1195-1177}$; lane 3, MVK CDNA after amplification with primer set $M V K_{-21--3}$ and $M V K_{1238-1219}$. The expected sizes of the fragments as calculated from the MVK cDNA sequence are 1186 and 1259 basepairs, respectively.

lymphocytes (Table 3). Most patients (17) had been sequenced also at the cDNA level and when the then determined genotypes were compared with the genotypes at the genomic DNA level no differences were found. Our analysis identified six novel point mutations, detected in five patients displaying the HIDS phenotype and one patient with the MA phenotype. Five of these mutations were found in patients that were heterozygotes for the novel mutation and the $1129 \mathrm{G}>\mathrm{A}$ (V377I) mutation. These mutations include an $\mathrm{A}>\mathrm{T}$ transversion at nucleotide 37 , which changes the lysine at position 13 into a stop codon (K13X), a $\mathrm{T}>\mathrm{C}$ transition at nucleotide 116, which changes the leucine at position 39 into a proline (L39P), a G > A transition at nucleotide 185, which changes the tryptophan at position 62 into a stop codon (W62X), a C > T transition at nucleotide 404, which changes the serine at position 135 into a leucine (S135L), and a G $>C$ transversion at nucleotide 447 , which changes the tyrosine at position 149 into a stop codon (Y149X). The patient carrying the K13X and V377I allele was described previously as a mild MA patient with considerable residual MK activity in lymphoblasts and lymphocytes. ${ }^{21}$ The presence of the V377I allele in conjunction with only moderate excretion of mevalonic acid in urine $(0.051-0.069 \mathrm{~mol} / \mathrm{mol}$ creatinine $)^{21}$ and the clinical data suggest that this patient in fact is a HIDS patient. The sixth novel mutation was a heterozygous $\mathrm{G}>\mathrm{T}$ transversion at nucleotide 442 , which changes the alanine at position 148 into a threonine (A148T). The HIDS patient carrying this allele was also a heterozygote for the I268T allele, which has been identified in several MA patients. ${ }^{16,17}$ The residual MK activity in fibroblasts from this patient $(1.6 \%)$ suggests that the A148T mutation, like the V377I mutation, is responsible for the HIDS phenotype.

Expression of $M V K$ mRNA in fibroblasts of patients with different genotypes

To examine whether one of the identified mutant alleles in MVK affect mRNA expression or stability, Northern blot analysis was performed using mRNA isolated from fibroblasts of patients with different genotypes and phenotypes (Figure 2). None of the different genotypes resulted in lower expression levels when compared with mRNA isolated from fibroblasts of control subjects, indicating that the identified point mutations have no effect on MVK mRNA expression or stability.

\section{Discussion}

Here, we report the genomic organisation of the gene encoding MK. The intron-exon boundaries were identified by amplification of intron sequences from genomic DNA using primer sets designed on the MVK CDNA. PCR products were sequenced and analysed for intron-exon boundaries. We found 11 exons ranging in size from 46 to $837 \mathrm{bp}$, with all intron-exon boundaries following the GTAG rule. Exon 1 encodes most of the $5^{\prime}$-untranslated region (UTR), exon 2 contains the ATG start codon and exon 11 contains the stop codon and the entire 3 '-UTR. 
Table 3 Mutations in the MVK gene and corresponding MK activities of patients with HIDS or MA

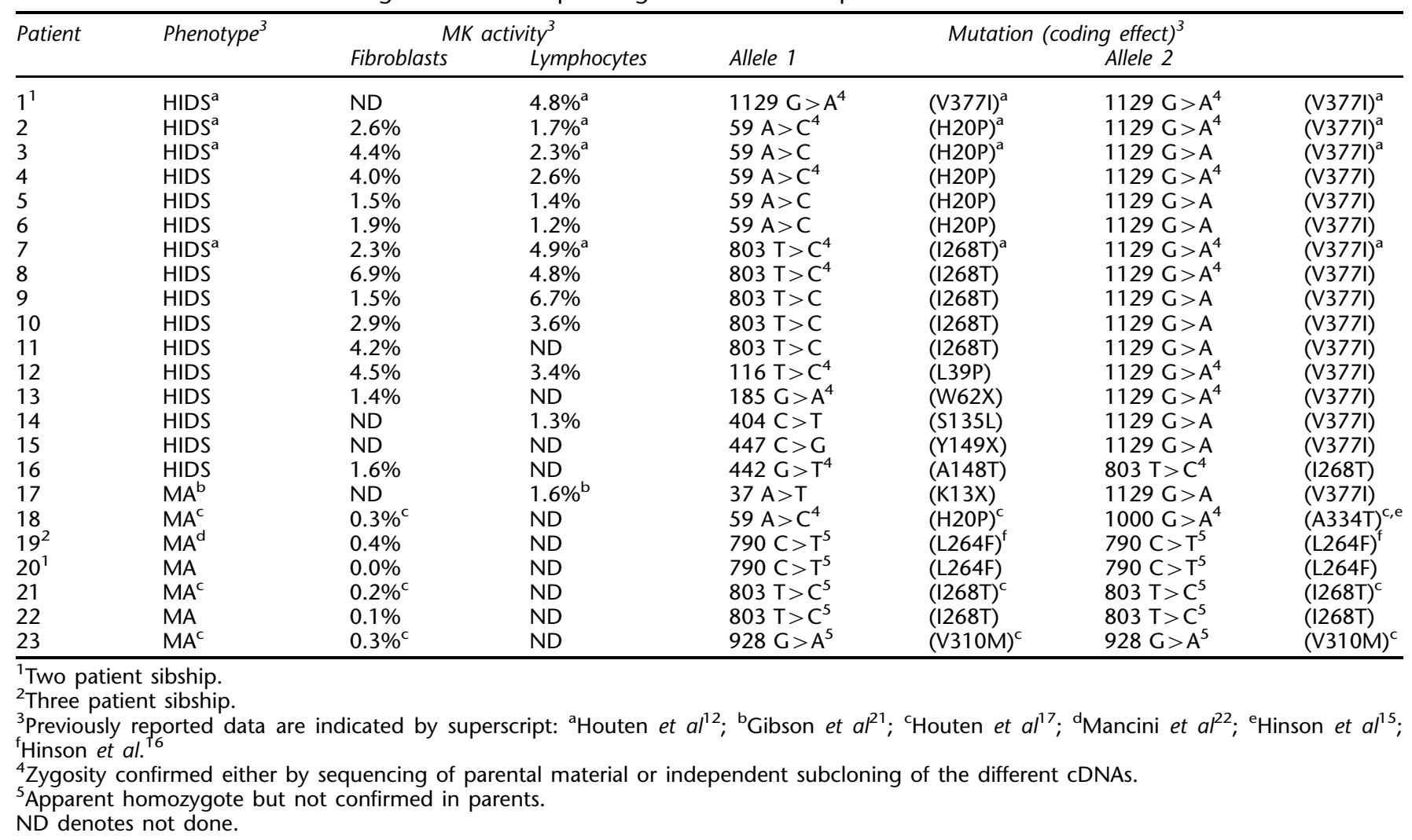

The introns vary in size from $379 \mathrm{bp}$ to approximately $4.2 \mathrm{~kb}$. The total size of the $M V K$ gene is approximately $22 \mathrm{~kb}$.

Exon 1 and 2 have been reported in two previous studies. Bishop et $a l^{23}$ studied the $M V K$ promoter region and found consensus sequences for a sterol regulatory element (SRE) and the Sp1 transcription factor (GenBank accession no. AF033345). The presence of an SRE in the MVK promoter region suggests a coordinate regulation of genes functioning in sterol biosynthesis. In their study, intron 1 was identified 15 bp upstream of the MVK ATG start codon. In addition, Graef $e a^{24}$ reported the insertion of hepatitis B virus DNA in intron 1 of the $M V K$ gene in a human hepatoma cell line. This led to the over-expression of hybrid transcripts (HBmk; GenBank accession no. X75311) arising from an $\mathrm{HBV}$ promoter and, as a consequence, the over-production of functionally active MK.

Three intron-exon boundaries also were identified after analysis of $M V K$ splice variants. In fibroblast and lymphocyte cDNA, deletions of exon 4 or exon 4 and 5 are rather frequent and sometimes even preferentially amplified in certain lymphocyte cDNA preparations (unpublished data), which greatly hampers cDNA mutation analysis of patient material. This exon skipping is most probably due to the presence of a weak splice acceptor site and/or branch point sequence. At the position of intron 3 also sometimes an insertion containing an Alu repeat was identified. The sequence of this insertion was not observed in the sequenced $5^{\prime}$ and $3^{\prime}$ ends of intron 3, suggesting that it is the result of a cryptic splice site in the unsequenced parts of this intron. All these splice variants encode truncated proteins. In mice, however, an in frame insertion occurs at the same position introducing 12 additional amino acids. Screening of the mouse EST database revealed that 2 of 5 identified EST sequences in this region contained this insert. This indicates that these splice variants could be of functional importance at least in mice. Finally, we also identified an mRNA with a deletion of exon 8 , while Graef $e a^{24}$ identified several clones with a deletion of exon 5. A deletion of exon 5 does not interrupt the reading frame of the gene, but results in an inactive MK protein. ${ }^{25}$

Most MVK mutations in patients with MK deficiency have only been determined at the cDNA level. We sequenced 17 HIDS and $10 \mathrm{MA}$ patients at the genomic DNA level. In all patients previously analysed at the cDNA level the genotype could be confirmed. In addition, we identified six novel point mutations in the MVK ORF, three of which were nonsense mutations resulting in early stop codons and truncated proteins. The other three missense mutations affect conserved amino acids. The A148T mutation was identified in a HIDS patient together with 


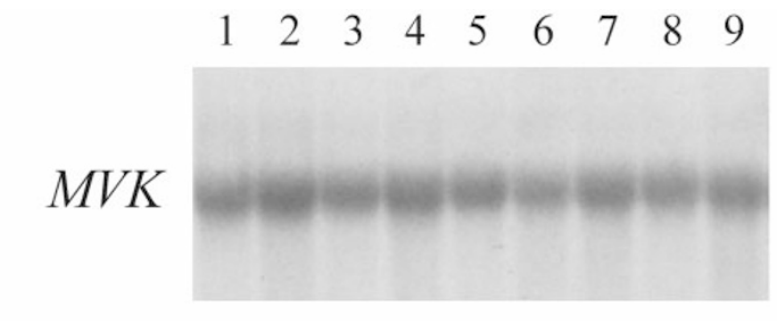

\section{GAPDH}

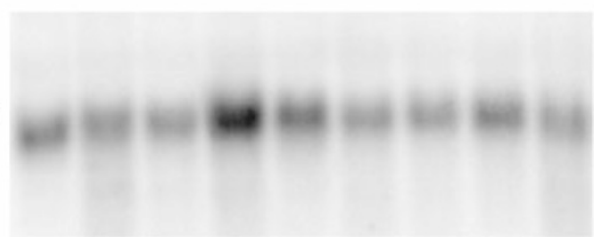

Figure 2 Northern blot analysis of $M V K$ transcripts from control, HIDS and MA fibroblasts. A blot containing $15 \mu \mathrm{g}$ of total fibroblast RNA from each subject was probed with $\alpha_{-}{ }^{32} \mathrm{p}$ labelled human MVK CDNA, subsequently stripped and reprobed with $\alpha-{ }^{32} \mathrm{P}$-labelled glyceraldehyde 3-phosphate dehydrogenase (GAPDH) cDNA. Lanes $1-3$, control subjects; lanes 4-9, patient $18,23,7,9,10$ and 13 , respectively.

the I268T mutation that has been identified in several MA patients. This suggests that the A148T mutation also leads to the HIDS phenotype as has been shown for the V377I mutation. Thus far, only one other HIDS patient has been described without the V377I mutation. This patient was a heterozygote for a mutation changing the proline at position 165 into a leucine (P165L) and the I268T mutation, ${ }^{11}$ which suggests that the P165L mutation also leads to the HIDS phenotype. The alanine at position 148 is part of a spatially conserved motif, which is present in all MK sequences, but also in several other metabolite kinases including galactokinase, homoserine kinase and phosphomevalonate kinase (ERG8) ${ }^{26}$ and has the characteristics of an ATP binding site $\left(\mathrm{GXGXXAX}_{(13-26)} \mathrm{K}\right) \cdot{ }^{14,26,27}$ Expression studies in $E$. coli will be necessary to evaluate the effect of this mutation, for example on ATP binding. One patient sibship diagnosed with HIDS was confirmed to be a homozygote for the V377I allele by sequencing of both parental and patient material at the genomic DNA level. This shows that homozygosity for this mild allele also leads to the HIDS phenotype, suggesting a complete penetrance.

The residual MK activity in our HIDS patients varied from 1 to $7 \%$, whereas residual MK activity in almost every MA patient was virtually undetectable $(<0.5 \%)$. Only one mild MA patient appeared to have considerable MK activity. ${ }^{21}$ The fact that this patient had a moderate excretion of mevalonic acid in urine, the clinical characteristics of HIDS and the V377I allele suggests that this patient is a HIDS patient.

So far, only one HIDS patient has been described with a potential splice site mutation. ${ }^{11}$ In addition to the $1129 \mathrm{G}>\mathrm{A}$ mutation this patient was a heterozygote for a 92 bp deletion in his $M V K$ cDNA corresponding to exon 2. The authors' suggestion that this deletion was the result of exon skipping due to a mutation in the splice site, is supported by the elucidation of the genomic organisation as reported in this paper. However, the actual mutation that leads to this skipping remains to be identified.

Northern blot analysis of mRNA from fibroblasts of patients with different genotypes revealed no effect of any of the tested mutations on mRNA stability or expression. This is in accordance with previous studies, which showed that although most mutations result in proteins with reduced enzyme activity when expressed in E. coli, they predominantly affect the stability of the MK protein as shown by immunoblot analysis. ${ }^{12,16,17}$

\section{Acknowledgments}

We are grateful to Drs Josette Mancini, Bruce Buckingham, Ralph Fingerhut, Alfried Kohlschuetter, Michele Brivet and Audrey Boutron for supplying cultured fibroblasts and lymphoblasts of their patients. HR Waterham is supported by a fellowship of the Royal Netherlands Academy of Arts and Sciences. We have completed a GenBank data request form on nucleotide sequence data. The accession numbers are as follows: AF217527, AF217528, AF217529, AF217530, AF217531, AF217532, AF217533, AF217534, AF217535, AF217536.

\section{References}

1 Goldstein JL, Brown, MS: Regulation of the mevalonate pathway. Nature 1990; 343: 425 - 430.

2 Fitzky BU, Witsch-Baumgartner M, Erdel $\mathrm{M}$ et al: Mutations in the delta-7-sterol reductase gene in patients with the SmithLemli-Opitz syndrome. Proc Natl Acad Sci USA 1998; 95: 8181 8186.

3 Wassiff CA, Maslen C, Kachilele-Linjewile S et al: Mutations in the human sterol $\Delta 7$-reductase gene at 11q12-13 cause SmithLemli-Opitz syndrome. Am J Hum Genet 1998; 63: 55-62.

4 Waterham HR, Wijburg FA, Hennekam RCM et al: Smith-LemliOpitz syndrome is caused by mutations in the 7-dehydrocholesterol reductase gene. Am J Hum Genet 1998; 63: 329-338.

5 FitzPatrick DR, Keeling JW, Evans MJ et al: Clinical phenotype of desmosterolosis. Am J Med Genet 1998; 75: 145-152.

6 Braverman N, Lin P, Moebius FF et al: Mutations in the gene encoding $3 \beta$-hydroxysteroid- $\Delta 8, \Delta 7$-isomerase cause X-linked dominant Conradi-Hünermann syndrome. Nat Genet 1999; 22: $291-294$.

7 Derry JMJ, Gormally E, Means GD et al: Mutations in a $\Delta 8-\Delta 7$ sterol isomerase in the tattered mouse and X-linked dominant chondrodysplasia punctata. Nat Genet 1999; 22: 286-290.

8 Grange DK, Kratz LE, Braverman NE, Kelley RI: CHILD syndrome caused by deficiency of $3 \beta$-hydroxysteroid- $\Delta 8, \Delta 7$-isomerase. $A m$ J Med Genet 2000; 90: 329-335.

9 König A, Happle D, Bornholdt D, Engel H, Grzeschik KH: Mutations in the NSDHL gene, encoding a $3 \beta$-hydroxysteroid dehydrogenase, cause CHILD syndrome. Am J Med Genet 2000; 90: $339-346$.

10 Hoffmann GF, Charpentier C, Mayatepek E et al: Clinical and biochemical phenotype in 11 patients with mevalonic aciduria. Pediatrics 1993; 91: 915 -921.

11 Drenth JPH, Cuissset L, Grateau G et al: Mutations in the gene encoding mevalonate kinase cause hyper-IgD and periodic fever syndrome. Nat Genet 1999; 22: 178-181. 
12 Houten SM, Kuis W, Duran M et al: Mutations in MVK, encoding mevalonate kinase, cause hyperimmunoglobulinaemia D and periodic fever syndrome. Nat Genet 1999; 22: 175 177.

13 Drenth JPH, Haagsma CJ, van der Meer JWM, The International Hyper-IgD Study Group: Hyperimmunoglobulinemia D and periodic fever syndrome: the clinical spectrum in a series of 50 patients. Medicine 1994; 73: $133-144$.

14 Schafer BL, Bishop RW, Kratunis VJ et al: Molecular cloning of human mevalonate kinase and identification of a missense mutation in the genetic disease mevalonic aciduria. J Biol Chem 1992; 267: 13229-13238.

15 Hinson DD, Chambliss KL, Hoffmann GF, Krisans S, Keller RK Gibson KM: Identification of an active site alanine in mevalonate kinase through characterization of a novel mutation in mevalonate kinase deficiency. J Biol Chem 1997; 272: 26756-26760.

16 Hinson DD, Ross RM, Krisans S et al: Identification of a mutation cluster in mevalonate kinase deficiency, including a new mutation in a patient of Mennonite ancestry. Am J Hum Genet 1999; 65: $327-335$

17 Houten SM, Romeijn GJ, Koster J et al: Identification of three novel missense mutations in mevalonate kinase cDNA causing mevalonic aciduria, a disorder of isoprene biosynthesis. Hum Mol Genet 1999; 8: $1523-1528$.

18 Hoffmann GF, Brendel SU, Scharfschwerdt SR, Shin YS, Speidel IM, Gibson KM: Mevalonate kinase assay using DEAE-cellulose column chromatography for first-trimester prenatal diagnosis and complementation analysis in mevalonic aciduria. J Inherit Metab Dis 1992; 15: 738-746.
19 Sambrook J, Fritsch EF, Maniatis T: Molecular cloning: a laboratory manual, 2nd edn. Cold Spring Harbor Laboratory Press: Cold Spring Harbor, NY, 1989.

20 Gibson KM, Hoffmann GF, Tanaka RD, Bishop RW, Chambliss KL: Mevalonate kinase map position 12q24. Chromosome Res 1997; 5: 150 .

21 Gibson KM, Hoffmann GF, Sweetman L, Buckingham B: Mevalonate kinase deficiency in a dizygotic twin with mild mevalonic aciduria. J Inherit Metab Dis 1997; 20: 391 - 394.

22 Mancini J, Philip N, Chabrol B, Divry P, Rolland MO, Pinsard N: Mevalonic aciduria in three siblings: a new recognizable metabolic encephalopathy. Pediatr Neurol 1993; 6: 243-256.

23 Bishop RW, Chambliss KL, Hoffmann GF, Tanaka RD, Gibson KM: Characterization of the mevalonate kinase 5 '-untranslated region provides evidence for coordinate regulation of cholesterol biosynthesis. Biochem Biophys Res Commun 1998; 242: 518 524.

24 Graef E, Caselmann WH, Wells J, Koshy R: Insertional activation of mevalonate kinase by hepatitis B virus DNA in a human hepatoma cell line. Oncogene 1994; 9: 81-87.

25 Graef E, Caselmann WH, Hofschneider PH, Koshy R: Enzymatic properties of overexpressed HBV-mevalonate kinase fusion proteins and mevalonate kinase proteins in the human hepatoma cell line PLC/PRF/5. Virology 1995; 208: 696-703.

26 Tsay YH, Robinson GW: Cloning and characterization of ERG8, an essential gene of Saccharomyces cerevisiae that encodes phosphomevalonate kinase. Mol Cell Biol 1991; 11: 620-631.

27 Potter D, Wojnar JM, Narasimhan C, Miziorko HM: Identification and functional characterisation of an active-site lysine in mevalonate kinase. J Biol Chem 1997; 272: 5741 - 5746. 